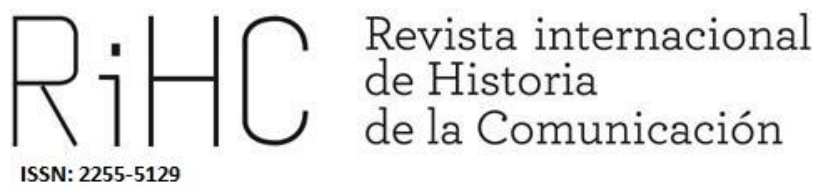

\title{
BAYER: MODERNIZACIÓN Y COSMOPOLITISMO CONTRA LOS SALTEADORES DE LA SALUD
}

Bayer: Modernization and Cosmopolitism against the Health Raiders

DOI: https://dx.doi.org/10.12795/RiHC.2020.i14.08

Recibido: $12 / 06 / 2020$

Aceptado: $15 / 06 / 2020$

Publicado: $15 / 06 / 2020$

Vanessa Fonseca González

ORCID (1) 0000-0003-0242-3843

Universidad de Costa Rica, Costa Rica

vanessa.fonseca@ucr.ac.cr 
Resumen: Según Adorno y Horkheimer, la publicidad es el elixir del capitalismo, es decir, el análisis del discurso y la industria publicitaria es fundamental para comprender la convergencia de fuerzas económicas, imaginarios sociales, identidades culturales y la cultura material que se deriva de ellas. En las primeras décadas del siglo XX, en el Diario de Costa Rica, Bayer es una de las marcas que destaca por publicitar productos acompañados de elaboradas ilustraciones y detalladas narraciones. Estas piezas publicitarias describen el sofisticado ethos moderno, caracterizado por un progreso cosmopolita que ofrece tanto nuevos placeres como nuevas preocupaciones y dolencias. Sin embargo, en piezas de similar formato a las anteriores, también se alerta a los consumidores sobre la preocupante circulación de preparaciones no autorizadas o falsificadas que atentan contra la salud de quienes, engañados, son víctima de los "salteadores de la salud". Este artículo analiza un conjunto de piezas publicitarias de 1920 que dialogan y compiten con publicidad de otros medicamentos contemporáneos de diferente procedencia. La perspectiva metodológica combina los estudios visuales con el análisis crítico del discurso, mientras que la perspectiva teórica se basa en los estudios de cultura material, historia del consumo y teoría crítica.

Palabras clave: Publicidad, productos milagro, Bayer, aspirina, modernidad, comportmiento del consumidor

\begin{abstract}
Following Adorno and Horkheimer, advertising is the elixir of capitalism, in other words, analyzing the advertising industry and its discourse is crucial to understand how economic forces, social imageries, cultural identities and material culture converge. In the threshold of the 20th century, Bayer appears among the brands advertised at Diario de Costa Rica. However, these advertisements outstand due to their ellaborate illustrations and storytelling that depict a sofisticated, cosmopolitan modern ethos. Beside the traditional ads promoting the use of aspirin as the epitome of modern science, Bayer published additional ads advicing consumers against non authorized or fake " me too " products, mimiquing the original Bayer formula and, consequently, threatening consumers health and wellbeing. This article analyzes a series of 1920's Bayer ads published at Diario de Costa Rica and establishes a dialogue among other contemporary " miracle product " brands from various origins. Discourse analysis and visual studies help to understand the corpus selected as multimodal texts and theories on consumer and material culture contribute to study how advertising naturalizes the modern consumer ethos while branded trustworthy products promise not only health improvements, but sophistication and cosmopolitism.
\end{abstract}

Keywords: Advertising, miracle products, Bayer Aspirin, modernity, consumer behaviour

\title{
Introducción
}

Desde tiempos inmemoriales, la especie humana ha buscado en la naturaleza no solo recursos alimenticios, sino una farmacopea vastísima para remediar los males que las vicisitudes de su evolución le han deparado. La búsqueda de soluciones a dolores, pestes y enfermedades es tan antigua como nuestra especie, pero la manipulación de los recursos naturales como remedios para la salud ha pasado por diferentes momentos que van desde el descubrimiento casual o la experimentación, la alquimia, el desarrollo 
de la química moderna y, hoy, hasta de la nanotecnología como horizonte posthumano en la búsqueda de salud y bienestar.

Hacia 1920, se anuncian en el Diario de Costa Rica y en muchos otros diarios costarricenses, varios productos que prometen aliviar gran cantidad de malestares. Los hay pensados para mujeres y sus dolencias particulares tales como el Compuesto Vegetal de Lydia E. Pinkham, las pastillas Grantillas, el Compuesto o Supositorios Mitchella o las píldoras de Brandeth. También los hay dirigidos a hombres para ofrecerles vigor, energía o fortaleza cerebral para enfrentar los retos de la vida moderna tales como el Tónico Velcas o la Cerebrina. Otros productos como los Laxoconfites o la Emulsión de Scott ofrecen a las madres purgas o mejorar la calidad de la produción de sangre en los más pequeños. Esta vorágine de promesas de sanación, vitalidad y bienestar responde a una conyuntura histórica en la que se empieza a naturalizar el tránsito de la medicina natural tradicional a la medicina moderna respaldada por la ciencia y especialmente por disciplinas tales como la química y la profesionalización de la farmacia y la práctica de la medicina moderna mediante la observación de cómo reaccionaban los pacientes a las prescripciones de diferentes preparaciones o fármacos.

La pandemia de la influenza o gripe española que cobra aproximadamente 500 millones de víctimas en todo el mundo se había extendido desde 1917. En Costa Rica, para 1920, la tercera ola de la pandemia era una realidad, junto con la fiebre amarilla y la malaria. Hoy se sabe que fue causada por el virus H1N1 y que su nombre le viene no por ser España el origen geográfico de la misma, sino por el hecho de que los reportes de la enfermedad en los diarios españoles de la época contabilizaron las víctimas sin manipular las estadísticas, como sí lo hacían muchos de los países involucrados en la Primera Guerra Mundial con el fin de no generar más desánimo entre sus poblaciones diesmadas no solo por la peste, sino también por la guerra. De ahí que los números reportados por los diarios españoles excedieran a los reportados por otros periódicos europeos. $^{1}$

Este artículo se centra particularmente en una serie de piezas publicitarias de Bayer para las tabletas de Aspirina (patentada en 1899) y Cafeína publicada en el Diario de Costa Rica entre enero y febrero de 1920. Discute cómo Bayer advierte a los consumidores consumir sólo la Aspirina original (Aspirina es la marca registrada por Bayer para el ácido acetilsalicílico) identificada por su empaque y la morfología particular de la tableta (la cruz de Bayer). Estos anuncios son evidencia de cómo la publicidad naturaliza el

1 Botey (2017, p. 104) estudió recientemente el desarrollo de la tardía pandemia de la fiebre española en Costa Rica en 1920 y afirma: "La epidemia se prolongó desde febrero a fines de abril, siendo marzo el más problemático, especialmente en San José, la capital. El Consejo informó, con datos incompletos, que las defunciones por influenza se elevaron a 1.200 personas en marzo. Una suma considerable para un país de menos de medio millón de habitantes." 
consumo de Aspirina Bayer como un comportamiento racional y moderno propio de consumidores informados y precavidos.

\section{Metodología}

Mediante un análisis semiótico visual, se establecerán correspondencias entre las narrativas del texto publicitario y las ilustraciones presentes en las piezas. Esta apreciación de la multimodalidad del texto se someterá a su vez a un análisis del discurso donde se ponderarán la retórica publicitaria, el discurso de la medicina moderna, la cultura material incipiente relacionada con el consumo de medicamentos con marca registrada y las condiciones históricas que enfrentaba Costa Rica en un año cuando la llamada influenza española, la malaria y la fiebre amarilla cobraron gran cantidad de víctimas y supusieron grandes retos de saneamiento para las instituciones públicas y el pueblo costarricense que desarrollaron nuevas prácticas de salubridad y consumo.

El corpus lo constituyen anuncios publicados entre enero y febrero de 1920 en el Diario de Costa Rica. Inicialmente se buscó publicidad de Bayer en Estados Unidos e Inglaterra ${ }^{2}$ correspondiente al mismo año. Este interés comparativo se debe a que una primera hipótesis de este trabajo intuía la publicidad de Bayer en Costa Rica respondía a tendencias internacionales comunes tanto en el mensaje publicitario como en el estilo visual. Sin embargo, esta revisión aportó resultados sorprendentes. Por un lado, la publicidad de Bayer de Estados Unidos e Inglaterra, por ejemplo, no muestra anuncios tan elaborados en tanto a diseño gráfico y narratividad o "storytelling", aunque sí coindide en el interés de insistir y prevenir a los consumidores sobre la necesidad de exigir el producto original o auténtico. Por otro, las ilustraciones presentes en los anuncios de Bayer del Diario de Costa Rica durante 1920 tienen rasgos comunes con la publicidad norteamericana de finales del siglo XIX en la que destacan los denominados Gibson Girl y Gibson Man que popularizó el ilustrador norteamericano Charles Dana Gibson a finales del siglo XIX y principios del XX y que se alimentaban a su vez de modelos arquetípicos femeninos detalladamente perfilados, especialmente en la representación del cabello y el ropaje que tienen como antecedente estilístico común a los pintores prerrafaelistas de finales del siglo XIX.

\footnotetext{
2 Esta búsqueda fue posible al accesar varios repositorios entre ellos California Digital Newspaper Collection del Center for Bibliographical Studies and Research de la Universidad de California en Riverside (https://cdnc.ucr.edu/); el John W. Hartman Center for Sales Advertising and Marketing History de la Universidad de Duke (https://library.duke.edu/rubenstein/hartman), los archivos históricos del Saturday Evening Post (https://www.saturdayeveningpost.com/issues/?issue-year=1920s), el repositorio British Newspaper Archive (https://www.britishnewspaperarchive.co.uk/) y la Biblioteca Nacional de Francia (www.bnp.fr), principalmente su colección Gallica.
} 
Hay varios aspectos históricos que son de relevancia para este año en particular. Primero, hacia 1920 Costa Rica enfrenta una emergencia sanitaria principalmente por la influenza española, la malaria y la fiebre amarilla. Tres años antes ha expirado el registro original de la Aspirina Bayer y esto facilitaba la circulación de preparaciones semejantes, no identificadas bajo una marca comercial. En este contexto la demanda por productos antipiréticos se incrementa. Los anuncios que constituyen el corpus están entre los que impulsan el consumo de Aspirina Bayer a través de una campaña publicitaria ${ }^{3}$ donde se asocia el ethos de consumo del producto a los deleites y malestares asociados con la vida moderna, al tiempo que se advierte a los consumidores sobre el peligro de adquirir preparaciones falsificadas.

El objetivo de este artículo se enfoca en estudiar cómo el discurso publicitario naturaliza el consumo de la Aspirina Bayer como un comportamiento razonable y moderno, propio de consumidores informados que no se dejan engañar por productos falsificados o por comerciantes o farmacéuticos inescrupulosos. El tono publicitario se articula perfectamente con situaciones de la vida cotidiana moderna donde los consumidores se enfrentan tanto a los deleites como a los retos de sociedades urbanizadas, cosmopolitas que apuestan a la medicina moderna y científica más allá de las creencias en productos milagro sin ningún fundamento. El primer apartado introduce la historia de la aspirina Bayer y su casi inmediata comercialización en mercados internacionales, principalmente en Inglaterra y los Estados Unidos a la vez que contextualiza y discute el consumo de medicamentos nostrum, propietarios y patentados hacia finales del siglo XIX en los Estados Unidos y la estrategia de Bayer para consolidar su monopolio en la venta de ácido acetilsalicílico bajo la marca Aspirina. El segundo compara los anuncios publicados en el Diario de Costa Rica con anuncios similares en periódicos británicos y norteamericanos de la misma época. El tercer apartado analiza cómo la campaña en estudio naturaliza el consumo de Aspirinas Bayer en un ethos moderno del que se derivan tanto deleites como malestares que ameritan soluciones rápidas, efectivas y confiables.

\section{Aspirina Bayer: La Droga del Siglo}

Friedrich Bayer y Johan Friedrich Weskett fundaron Bayer en 1863 en Barmen, un distrito de la actual ciudad de Wuppertal en Alemania. En los albores de la segunda revolución industrial, se destacaron como empresarios en la industria de tintes

3 Se puede considerar esta una campaña ya que las piezas guardan coherencia y cohesión gráfica. El mensaje tiene un mismo objetivo claro y preciso y buscan posicionarse diferenciadamente en la mente del consumidor, ya sea para asegurar su fidelización o para lograr su conversión, es decir, para que acepte y compre su producto mediante estrategias persuasivas visuales y retóricas. 
sintéticos derivados del alquitrán de hulla, principalmente enfocados en la cada día más poderosa industria textil europea. Según los archivos históricos de la compañía Bayer, en un sector cada vez más competitivo, la internacionalización era una forma de diferenciarse para generar mayor competitividad. Este énfasis hizo que la compañía creciera de 3 empleados en 1863 a 300 en 1881 (Bayer: 2020). A partir de 1881, la compañía se desarrolla internacionalmente y además invierte en un laboratorio propio del que eventualmente saldría la droga del siglo, el ácido acetilsalicílico al que la compañía bautizaría con la marca Aspirina. Sin embargo, la historia del ácido acetilsalicílico es mucho más antigua, los salicilatos se pueden obtener de la corteza del sauce o de la planta de mirto y son ingredientes comunes en las farmacopeas antiguas tanto sumerias, griegas, egipcias o romanas donde se destacan sus propiedades analgésicas, antipiréticas o antiinflamatorias.

Jeffreys (2004) eruditamente narra, desde diversos periodos y geografías, el camino recorrido por científicos, médicos y muchos otros en la búsqueda de aislar el ácido acetilsalicílico para lograr un medicamento poderoso contra la inflamación, la fiebre y como analgésico. Sin embargo, respecto a Bayer, la historia de la Aspirina se relaciona con Arthur Eichengrün y Felix Hoffman, dos químicos alemanes contratados por los laboratorios Bayer. Varias versiones existen sobre quién es el verdadero responsable de sintetizar la droga del siglo, pero ambos, sin duda, investigaron de qué forma podía lograrse incrementar o disminuir la toxicidad de algunas sustancias y pusieron en práctica diversos procesos de acetilización. De esta forma lo que hoy se conoce como un nombre genérico, aspirina, nace de una etimología química: $A$ referida al grupo acetil y spirina derivado de spiriae ulmaria, planta conocida como filipéndula ulmaria o reina de los prados como fuente de proceso de acelitización.

Hoffman logró sintetizar el ácido acetilsalicílico y la heroína ${ }^{4}$ en 1897 , solo a unas cuántas semanas de diferencia, aunque ya la heroína había sido sintetizada anteriormente por un químico inglés en 1874. Desde 1888, Bayer había logrado obtener y comercializar la fenacetina como analgésico. Fue una de las primeras drogas sintéticas efectivas en la reducción de la fiebre. Hoffman logra sintetizar el ácido acetilsalicílico mediante un procedimiento diferente y logró un resultado más puro y estable al alcanzado por otros químicos anteriores tanto alemanes como franceses. Bayer aplicó para la patente en Alemania, pero se le denegó argumentando que en realidad no se trataba de un producto nuevo, ni de un proceso de sintetización diferente, ya que había habido procesos de acetilización anteriores. La patente de la marca Aspirina data del 6 de marzo de 1899, pero como marca registrada, no como patente de un nuevo producto. Aunque se va a producir en Alemania en un inicio, los directivos de Bayer inspirados por

4 Bayer comercializó la heroína como medicamento sin prescripción como un antídoto contra la tos y el tratamiento de la tuberculosis y la neumonía desde 1899 hasta 1924 cuando la FDA (Federal Drug Administration) la prohibió excepto en casos médicos extremos. Según Edwards (2011), en España Bayer promocionó la heroína para evitar y suprimir la tos en niños. 
su espíritu de expansión internacional, optan por patentar la aspirina en sus dos mercados potenciales más grandes: Inglaterra (22 de diciembre de 1898) y en Estados Unidos (27 de febrero de 1900).

La historia de Bayer en las dos primeras décadas del siglo XX se caracteriza por la lucha por defender su posición en el mercado como marca registrada y la amenza de la industria química y farmacéutica incipiente en la participación de ese sector industrial. Varios estudios (Applegate 1998, McTavish 1999, Jeffreys 2007) coinciden en que la batalla que enfrentará Bayer en Inglaterra y en los Estados Unidos en la primera década del siglo XX en relación con los registros adquiridos en ambos países es una mezcla de la creciente regulación de la industria farmacéutica, el desarrollo de la Primera Guerra Mundial y las pugnas comerciales entre quienes apuestan por un mercado más abierto o participativo frente al monopolio establecido por Bayer al patentar la Fenaticina (1887) y luego la Aspirina (1900) como producto diferenciado, a pesar de que se conocían y existían procesos de acetilización anteriores.

\subsection{Medicamentos Patentados versus Productos éticos: De la aprobación real al mercadeo directo}

La historia de la evolución de las marcas demuestra que siempre ha existido la necesidad de distinguir los productos para conferirles autenticidad, legitimidad, calidad estampando ya el apellido del artesano, la denominación de origen del producto, el reconocimiento de una autoridad para su circulación en territorios específicos, etc. En la Inglaterra del siglo XVIII las denominadas "Patents of Loyal Favor" eran medicamentos propietarios que tenían el apoyo real para su producción y circulación. Su distribución y venta era libre, sin embargo, el hecho de distribuirse bajo la protección de la patente real las distinguía de otros productos que, pudiendo ofrecer los mismos efectos, no contaban con dicha aprobación. El uso y consumo de estos productos se traslada a la América colonial y fueron comunes hasta ya entrado el siglo XIX, de ahí su nombre nostrum remedium (nuestro remedio) o simplemente nostrum (Dysktra: 1955).

Con la Revolución Industrial, la cada vez más creciente industria farmaceútica ve la necesidad de regular y proteger nuevos productos y procesos, ya sea por medio de una marca registrada o por medio de una patente. Sin embargo, con el tiempo, muchos fabricantes industriales de medicamentos en Estados Unidos, cada vez más cansados de los nostrum y de algunos productos patentados que se presentaban como "productos milagro" optan por dos estrategias: primero, no publicar publicidad en periódicos o revistas de distribución masiva y, segundo, no distribuir sus preparaciones directamente al consumidor final, sino solamente bajo prescripción o mediante la distribución de pequeñas muestras directamente a médicos o farmacéuticos para que las probaran y 
recomendaran directamente en publicaciones profesionales. Estas prácticas se consideraban éticas, pues independientemente de si se trataba de una marca registrada (cuyos ingredientes eran secretos) o una patente (cuyos ingredientes eran públicos) lo importante era regular cada vez más la producción distribución y consumo para controlar más eficientemente, por un lado, a los medicamentos milagro y por otro a los traficantes de medicamentos auténticos que, aunque de calidad y origen conocido como la Fenaticina de Bayer, muchas veces se introducía a los Estados Unidos como contrabando desde Canadá o México con el fin de venderla a menor costo que la directamente importada de Alemania o la producida en Estados Unidos, que resultaba más costosa por gravámenes impuestos (Jefferys, 2007: 83).

Comprender la diferencia entre los nostrum, las medicinas patentadas para uso farmacéutico o industrial y las registradas como marcas es fundamental para entender el rol que Bayer tuvo en el desarrollo de la industria farmacéutica norteamericana y su impacto en otras regiones del mundo. McTavish (1999) establece esta diferencia y subraya el uso de la publicidad y otras estrategias de promoción en el desarrollo de la industria farmacéutica en los Estados Unidos:

That part of the American drug industry that evolved during the nineteenth century to supply the needs of pharmacists and physicians always prided itself on been morally superior to the other, perhaps better-known branch of the trade the nostrum "patent medicines" whose outrageous claims to cure any and all diseases with special formulae and secret ingredients, accompanied by aggressive and imaginative advertising, ofended the profesional sensibilities of doctors and druggist alike. (1999: 3)

Los nostrum no necesitaban prescripción, se vendían directamente al consumidor final, por eso la publicidad jugó un papel importantísimo en su posicionamiento en la mente de los consumidores. Conforme la industria farmaceútica se va especializando y se establece un mayor diálogo entre la práctica médica, la observación de resultados de prescripciones en pacientes (ya por farmacéuticos profesionales o médicos) y el desarrollo de ciertos fármacos, el uso de nostrum y marcas registradas con fórmulas secretas se hizo cada vez más sospechosa y ofensiva para las publicaciones profesionales (revistas o boletines de asociaciones médicas o farmacéuticas) donde se optó por eliminar la promoción o publicidad de estos preparados y de los productos patentados en aras de mayor objetividad y distancia. En este contexto ingresa Bayer en el mercado farmacéutico norteamericano. Las patentes tenían una vigencia de 17 años. Una vez transcurridos vencía y cualquier fabricante podía replicar la preparación ya fuera con el mismo nombre o con otra marca que lo diferenciara.

La paradoja de Bayer empezó con la Fenatecina que patentó en 1887 como analgésico muscular y antipirético. Carls Duisberg, Oskar Hinsberg y Martin Herzberg (Jacome 2003, Jeffreys 2007, Bayer 2020) químicos de los laboratorios Bayer empezaron a 
experimentar con derivados del alquitrán como la acetanilida. A Hinsberg se le atribute el descubrimiento de la fenacetina.

De ahí que, antes de la comercialización de la Aspirina, Bayer era una marca líder en la comercialización de la fenaticina en mercados como Estados Unidos o Inglaterra. En el desarrollo del capitalismo, la producción de diferencia es fundamental para posicionar un producto en la mente de los consumidores, es así como nace la cruz de Bayer.

\subsection{La Cruz de Bayer. Diferenciación y Estrategia de Marca}

Como todo mito fundacional, la "cruz de Bayer" marca patentada y logo de las tabletas de aspirina tiene al menos dos versiones. La primera indica que fue diseñada por Hans Scheider, un empleado de Bayer en Alemania en 1904. La segunda relata que otro empleado de Bayer, el Dr. Hugo Schweitzer, quien trabajaba en las instalaciones de la empresa en Nueva York, la diseñó como una estrategia para acortar y hacer más legible el nombre de la compañía (Farbenfabriken vormals Friedr. Bayer \& Co., Elberfeld) al promocionarla en la comunidad médica y farmacéutica en los Estados Unidos (Bayer, 2020).

La cruz Bayer es un ingenioso mecanismo de recordación y valor de marca. Consiste en un acrónimo construido por la palabra Bayer deletreada de forma vertical y de forma horizontal que representa una cruz cuyo axis es la $Y$ griega común al eje $X$ y al $Y$. Ese ejercicio de síntesis gráfica culmina con un círculo que rodea el acrónimo constituyéndolo en una especie de sello.

Logo Life (2012) ofrece una cronología del desarrollo del logo de Bayer desde 1881 hasta el presente. No sorprende descubrir que, en sus inicios, la marca como estrategia de diferenciación establece un diálogo entre el logo y la iconografía heráldica: Un escudo, un león y los nombres de la fábrica y su fundador, muy propio de la revolución industrial. Entre 1886 y 1895 el logo se hace más complejo como ilustración, pero sigue representando en 1895 a un león alado que se posa sobre el mundo con su garra derecha mientras que en la izquierda sostiene el símbolo de la medicina, la vara o el báculo de Asclepio. Ya para 1905, el logo se simplifica a la cruz Bayer que pasa por varios procesos de síntesis hasta llegar al que conocemos hoy.

Desde un punto de vista mercadológico, el acierto de la cruz Bayer como identificador del producto, como prueba de su autenticidad fue la estrategia de diferenciación frente a otros productos químicamente idénticos pero que circulaban como preparaciones en polvo, en tabletas sin identificar o en empaques diferentes al usado por Bayer. La aspirina se patenta en 1900 lo que hace que ya iniciada la Primera Guerra Mundial hacia 1914, la espada de Damocles pendiera sobre la compañía que próxima a la expiración 
de la patente debía enfrentar la posibilidad de que otros fabricantes la produjeran y vendieran sin ninguna restricción. Es importante notar que, del logo de 1905, donde aún aparecen el nombre de la compañía en alemán, al utilizado internacionalmente hay cambios significativos. En este último, se elimina todo texto en alemán probablemente para que el creciente sentimiento antigermánico no afectara las ventas del producto. La siguiente sección describe cómo la publicidad de Bayer en Costa Rica reacciona ante este contexto comercial en 1920.

\section{Sobre malos volatineros, escamoteadores, asaltantes y piratas}

El 1 de febrero de 1920, Bayer publica en el Diario de Costa Rica un anuncio titulado "Los escamoteadores de la salud" 5 . Típico del formato publicitario de la época, es abundante en texto y no menos prolijo en la ilustración:

Si usted tropieza con un escamoteador de arrabal, lo más seguro es que se abstenga de unirse a las gentes ignorantes y cándidas que le hacen corro, por que ni gusta que lo engañen con artimañas groseras, ni quiere que su dinero vaya a manos de charlatanes.

Acompaña a este texto una ilustración donde se observa una arquitectura asociada al medio oriente y varias personas vestidas con turbantes y velos que rodean asombradas a un encantador que hace salir una rosa de su pie, mientras toca una campanilla justo sobre él. El texto es claro en apelar al lector a diferenciarse de las muchedumbres ignorantes por dos elementos: su conocimiento y discernimiento de cómo invertir su dinero. Lo que empieza con una escena hipotética pronto pasa a ser una metáfora visual de quien compra medicamentos falsificados, de dudoso origen y calidad. El texto continúa: “¿Pero es usted igualmente precavido cuando se trata de ciertos comerciantes escamoteadores? No le dé oídos a quien le brinda unas tabletas sospechosas diciéndole que "son iguales a las legítimas". Eso es una impostura con que se le quiere seducir creyendo que Ud es un ignorante". El discurso publicitario se presenta como un guardián de la salud pública. La verdad del discurso publicitario se construye con una retórica muy sutil. Por una parte, una metáfora visual y por otra, la muestra del logo Bayer para legitimar la autenticidad y absoluta originalidad del producto. En esta pieza publicitaria covergen el "branding" o la estrategia de marca y un esfuerzo por diferenciar el producto

5 Diario de Costa Rica, 1 de febrero de 1920, p. 3. 
de otras preparaciones falsificadas o copiadas que claman ofrecer los mismos beneficios, sin mostrar la marca.

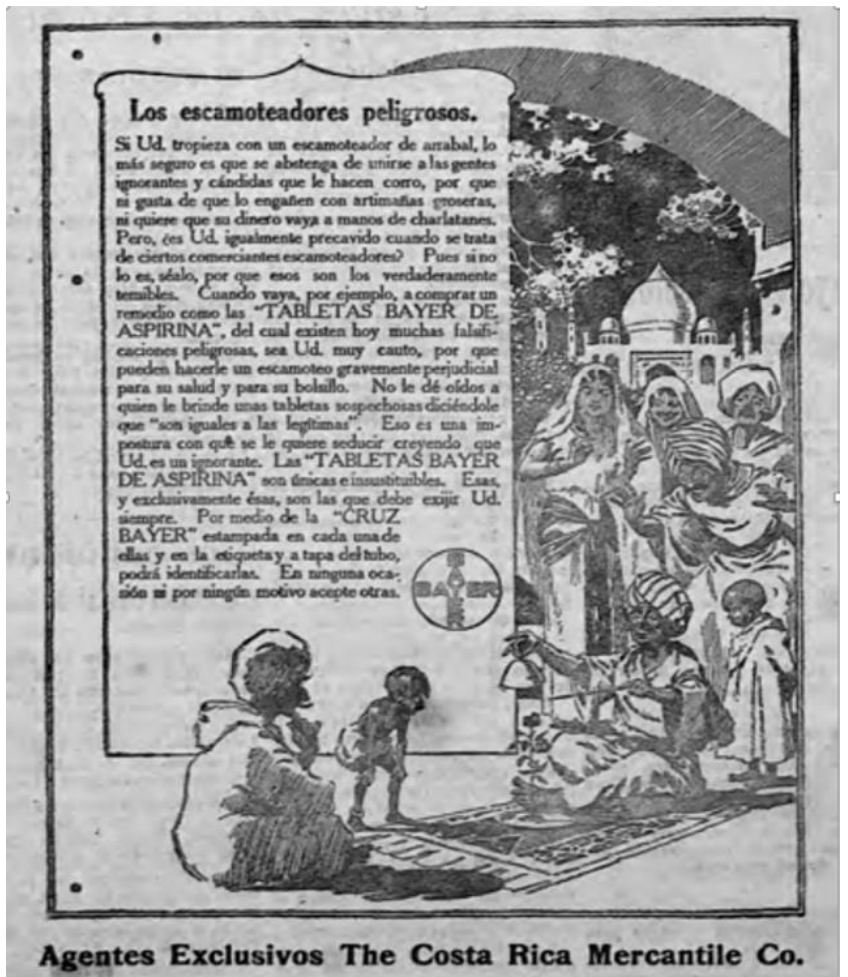

Figura 1. Diario de Costa Rica, 1 de febrero de 1920 p 3

La historia del desarrollo de la publicidad va de la mano con la racionalización de varios de los metarrelatos de la modernidad tales como el progreso, la libertad o la democracia. Los productos y servicios resultan atractivos no solo porque representan innovaciones que reestructuran las esferas pública y privada, sino porque ofrecen a través del consumo la consolidación y reproducción del sistema ideológico. Le prometen al consumidor "sentirse" moderno al ejercer su derecho de escoger $y$, al hacerlo, experimentar libertad y expresar su individualidad moderna.

El surgimiento de la publicidad como industria en las primeras décadas del siglo XX es fundamental para la consolidación de la lógica del capitalismo como la impronta de esos tiempos modernos. En consecuencia, para legitimizar el conocimiento que produce el discurso publicitario, es esperable que se apropie de una retórica basada en el discurso científico y en el énfasis en la racionalidad que, junto con la estandarización, la urbanización, la industrialización y el consumo masivo, caracterizan al paradigma moderno. En este anuncio hay una apelación al lector en cuanto consumidor racional e informado.

Sin embargo, los anuncios analizados muestran influencia tanto de la publicidad europea como de la norteamericana. El anunciante defiende un estilo publicitario híbrido. Por un lado, la ilustración se convierte en un símil de la situación experimentada por aquellos 
consumidores incautos que creen en "los escamoteadores de la salud" como los ignorantes creen a un encantador. Piezas con una retórica semejante son "Un Mal volatinero"6, "Los Piratas Modernos"7, los "Asaltantes de la Salud" y "Una tabla sobre el abismo". En todos ellos se advierte sobre el peligro de farmacéuticos o comerciantes que engañan y estafan a sus clientes con preparaciones falsas. Por otro, la publicidad que enfatiza la autenticidad del producto y lo muestra en la ilustración es más común en Europa, donde se privilegiaba, lo que tanto De Grazia (2005) como Spicka (1997) denominan como Ding an sich o, el producto en sí mismo.

Similar a otros anuncios en revistas americanas de la década de los 1920 o 30, los anuncios de Bayer publicados en el Diario de Costa Rica en 1920 tienen un texto relativamente largo en el que se busca que el lector se sienta identificado con los personajes o la "historia" que se narra. Tal y como lo discute Roland Marchand en Advertising The American Dream. Making Way to Modernity 1920 -1940, se intenta situar el producto en un contexto social que guste al lector y provoque su deseo, temor o la esperanza de adquirirlo. Simultáneamente, el texto del anuncio y el logo de Bayer describen gráfica y textualmente al producto en sí. Hacia el final del texto se lee: "Las "TABLETAS BAYER DE ASPIRINA" son únicas e insustituibles. Esas y exclusivamente esas son las que debe exijir (sic) Ud. Siempre. Por medio de la CRUZ BAYER. Estampada en cada una de ellas y en la etiqueta y la tapa del tubo, podrá identificarlas. En ninguna ocasión, ni por ningún motivo acepte otras". Los dos estilos publicitarios, el norteamericano más propenso a la "narrativa" y el europeo, más enfocado en el producto en sí coinciden en esta campaña analizada.

Si se compara este anuncio con la publicidad impresa de Bayer en Estados Unidos y en Inglaterra durante la misma época notaremos que es muy similar, pero su ilustración dista de la escena orientalista anteriormente descrita o de la complejidad de las ilustraciones en la prensa costarricense. En varios diarios ingleses se publican anuncios más simples, pero con el mismo caveat para los consumidores. Estas piezas enfatizan el producto en sí:

6 Diario de Costa Rica 13 de enero de 1920 p 6

7 Diario de Costa Rica 26 de febrero de 1920 p 3 


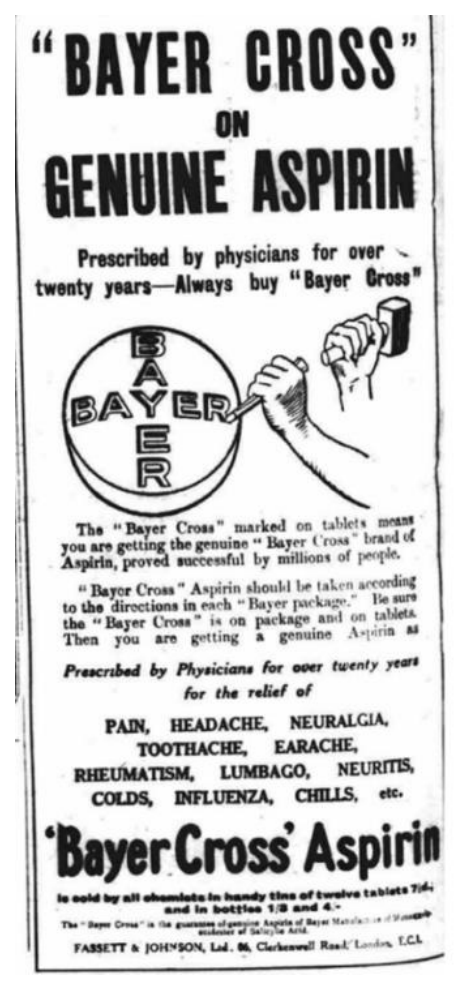

Figura 2 Sheffield Independent, 19 de diciembre de 1921 p 8

Otros diarios ingleses que muestran este mismo anuncio con variantes en la ilustración son el Manchester Evening News de Lancashire ${ }^{8}$ y el Yorkshire Evening Post ${ }^{9}$. Las diferentes ilustraciones son una mano con un cincel tallando el nombre Bayer en la tableta, una lupa o una mano firmando connotando autenticidad. Aquí se enfatiza un meticuloso proceso de compra que va desde la búsqueda del producto original, escoger el empaque distintivo, verificar el número exacto de unidades por cada envase, hasta seguir las instrucciones de cómo consumirlo. Del producto se enfatiza su morfología "la tableta con la Cruz Bayer" y las dolencias que podía remediar. Estos anuncios presentan la Aspirina Bayer como un medicamento recomendado por médicos por más de 20 años. Una cantidad importante de doctores y farmacéuticos la respaldaba, recomendaba y prescribía por encima de otros preparados semejantes, que no se vendían ni con la Cruz Bayer, ni en las presentaciones y empaques descritos en el anuncio y, además, millones de consumidores satisfechos habían naturalizado el uso del producto mediante la comunicación personal, la forma más efectiva de publicidad. 
Otros anuncios en diarios norteamericanos muestran a la publicidad de Bayer como un "guardián de la salud" ante sus compradores potenciales. The Standard Union de Brooklyn, Nueva York ${ }^{10}$, advierte a sus lectores: "Don't buy Aspirin in a Pill Box!". De semejante manera The Buffalo Enquirer"11 de Buffalo, Nueva York, indica: "Name Bayer on Genuine Aspirine". The New York Times publica otro anuncio ${ }^{12}$. Lo encabeza el título "Genuine Aspirine" al que sigue un subtítulo: "Bayer introduced Aspirins to physicians 19 years ago - Always say "Bayer". La ilustración muestra una huella digital humana, a su derecha, una mano imprime su huella en un papel, al lado de la huella. A la derecha, y del mismo tamaño que la huella digital humana, se muestra una tableta con la Cruz de Bayer como sinónimo de autenticidad. En el texto que sigue se lee: "The Bayer Cross is the thumb-print of genuine Bayer Tablets of Aspirin. It protects you against imitations and possitively identifies the genuine world-famous aspirin prescribed by physicians for over nineteenth years. Insist on an unbroken package of genuine "Bayer" Tablets of Aspirin, which contains proper directions".

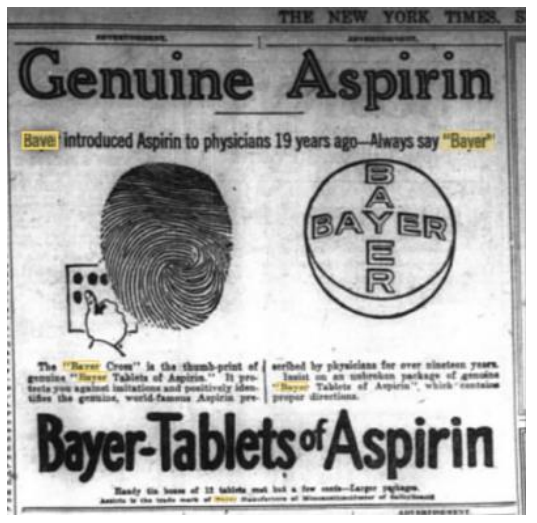

Figura 3. San Francisco Chronicle, de julio 1920, p, 8

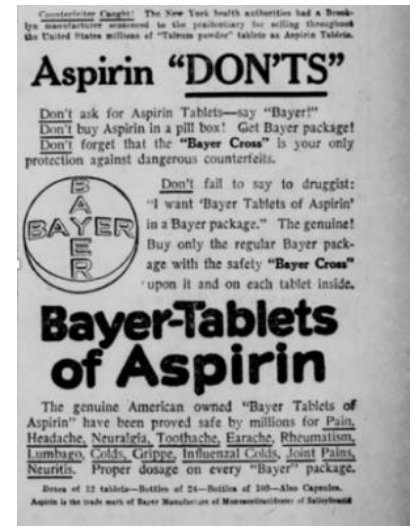

Figura 4 Los Angeles Evening Herald ${ }^{1} 11$ Volumen XLIV Number 170, 19 de Mayo 1919, p. 9

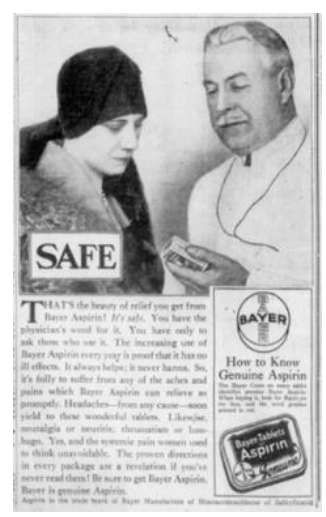

Figura 5 The Baltimore Sun, 17 de febrero de 1920 p. 52

10 Standart Union, 27 de abril de 1919, p.12

11 The Buffalo Enquirer, 19 de febrero de 1920, p. 3

12 New York Times 25 de julio de 1920 p 89. Otros periódicos que publican el mismo anuncio son el San Francisco Cronicle y Chattanooga Daily Times (Tennesse) 24 de setiembre de 1920, p. 11. 
Los anuncios en diarios de la costa oeste de los Estados Unidos muestran publicidad en la que se insiste en cómo comprar Aspirina y qué empaque y producto es el original. En Los Angeles Evening Herald se lee: “Don't ask for Aspirin Tablets - say Bayer. Don't Buy Aspirin in a pill box! Get Bayer package! Don't forget that the Bayer Cross is your only protection against dangerous counterfeits". Es importante señalar la sinergia que deben establecer el discurso médico de principios del siglo XX con el discurso de anunciantes de productos farmacéuticos y la incipente profesión publicitaria en busca de legitimación. En "Un Mal buen volatinero" ${ }^{13}$ se lee:

El droguista que trata de sostener un artículo tan sospechoso como las tabletas de aspirina anónimas o de marca desconocida, intenta un equilibrio imposible y no logra otra cosa que ponerse en ridículo antes las gentes sensatas" (...) Recuerde siempre que defenderse de las medicinas falsificadas es tan importante como defenderse de las enfermedades mismas.

En un tono semejante "Los piratas modernos"14 advierte:

Quienes en tiempos remotos asaltaban a mano armada las naves indefensas no eran más alevosos que el droguista de nuestros días que atenta, a mansalva y sobre seguro, contra la salud de un cliente confiado, vendiéndole un substituto peligroso. En vez de una medicina legítima.

Una vez más razón, ciencia y modernización distinguen al consumidor moderno y sensato del ignorante. Otro anuncio titulado "Lámparas nuevas por lámparas viejas"15 indica: "Actualmente hay en el mercado muchas preparaciones que llevan el nombre de tabletas de aspirina pero que no son sino polvo de talco o de mezclas sospechosas que pueden causar daño al organismo."

En la "Tabla sobre el Abismo" 16 se lee: "No acepte ninguna de las preparaciones anónimas o de marca desconocida que le ofrezca el droguista asegurándole que son tan buenas como las legítimas". Finalmente, en Los "Salteadores de la salud"17 se repite la advertencia de cuidarse de farmacéuticos inescrupulosos: "La bolsa o la vida" es el dilema que el salteador de caminos ofrece al viajero indefenso. El droguista que maliciosamente le vende a Ud. Una medicina falsificada, ni siquiera le concede ese

13 Diario de Costa Rica 13 de enero de 1920, p. 6

14 Diario de Costa Rica 20 de enero de 1920 p. 6

15 Diario de Costa Rica 8 de febrero de 1920 p. 2

16 Diario de Costa Rica 27 de enero de 1920 p. 8

17 Diario de Costa Rica 12 de febrero de 1920 p. 8. En el ABC de Madrid del 14 de diciembre de 1919 p 28 u anuncio ilustrado promociona el carbón de Belloc con un tono prácticamente idéntico a este y "titulado La Bolsa o la Vida." 
privilegio de escoger sobre dos males, sino que le ataca "la bolsa y la vida", puesto que le roba su dinero y ponen en grave peligro su salud".

La publicidad de Bayer en España muestra para 1919 la misma preocupación que los anuncios de Estados Unidos, Inglaterra y Costa Rica. En 1919 en el ABC de Madrid un anuncio de Bayer indica ${ }^{18}$ : "Todos los farmacéuticos honrados desean despachar lo que el médico prescribe y lo que le piden sus clientes. Fábricas sin escrúpulos han falsificado la Aspirina, la que sustituye por una droga a veces nociva".

Todos los anuncios analizados son piezas que evidencian la lucha de Bayer por defender la originalidad del producto una vez vencida la vigencia de su marca comercial y en un mercado farmacéutico cada vez más regulado $y$, a la vez, afectado por el antigermanismo ${ }^{19}$ derivado de la Primera Guerra Mundial y de la proliferación de preparados de ácido acetilsalicílico sin identificación. El siguente apartado analiza cómo las tabletas de Aspirina Bayer, en tanto medicamento confiable y científico, se recomiendan contra los excesos, fatigas, placeres y dolencias que imponen los tiempos modernos.

\section{Aspirina Bayer: solución eficaz a los malestares y deleites modernos}

Los anuncios de Aspirina Bayer en el Diario de Costa Rica en 1920 muestran un estilo ilustrativo muy particular que recuerda en su formato a la publicidad norteamericana en diarios o revistas ilustradas tales como Ladies Home Journal o el Saturday Evening Post. Guardan características formales y una retórica consistente como para que los consideremos una de las primeras campañas impresas de Bayer en el país. De estas ilustraciones y textos también llaman poderosamente la atención la complejidad que presenta la técnica ilustrativa y la clara influencia de los modelos publicitarios popularizadas por Charles Dana Gibson con la Gibson Girl y el Gibson Man. Pitz (1969) describe estos prototipos de género de la siguiente manera:

These two types were a handsome, youthful pair, incredibly competent and assured. They could smile, but seldom laughed. They moved through a world that did not seem too demanding. Courteous, secure and serene, they have an Anglo-Saxon attractiveness which seem to conquer

18 ABC de Madrid el 18 de diciembre de 1919 p.16

19 Un anuncio de aspirina francesa en el Paris Midi del 26 de enero de 1915 p 2 sugiere: "Ne prenez que L' Aspirine "Usine des Rhöne" pure de tout mélange allemande". 
all posible problems. They wore fashionable clothes with selfconciousness distinction; their gestures were patrician. Yet they did not seem remote - not too remote. For a rapidly

expanding middle class, busily climbing up the social ladder, here was a model of what they could hope to reach. (Pitz, 1969: 105).

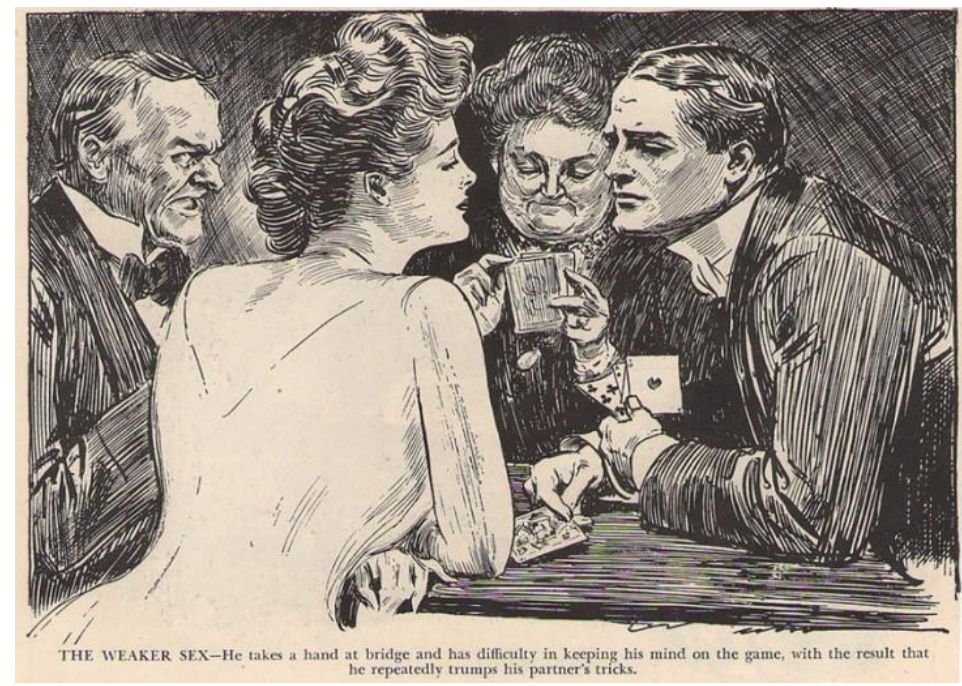

Figura 6 The Weaker Sex circa 1908, Charles Dana Gibson ${ }^{20}$

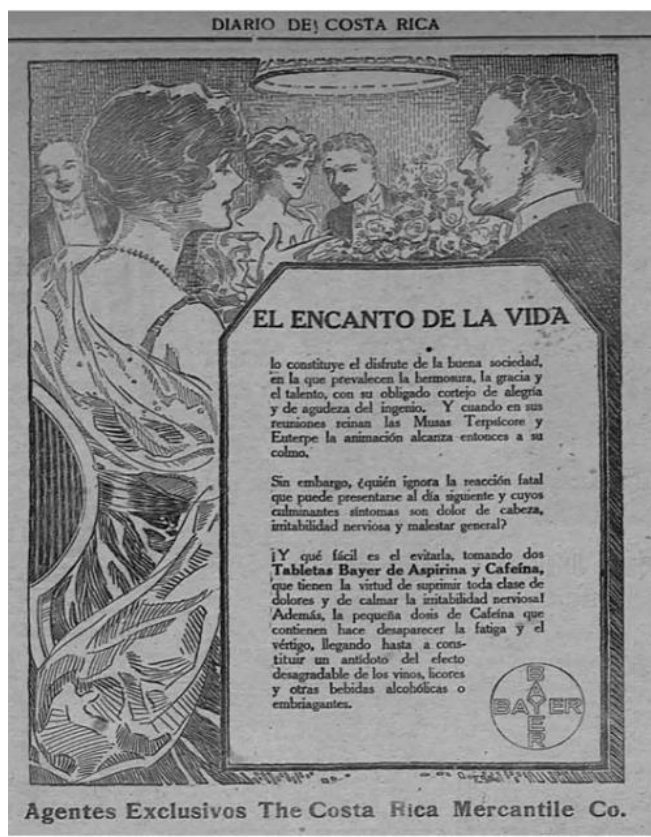

Figura 7 Diario de Costa Rica, 3 de enero de 1920, p. 6

20 Disponible en internet (1-21-20202): https://www.worthpoint.com/worthopedia/charles-danagibson-girl-ap-print-1760720137 
"El encanto de la vida" ${ }^{21}$ y "La Vida es deliciosa" 22 ambos ilustran a cinco adultos (3 hombres y 2 mujeres) sentados a la mesa disfrutando de bebidas y conversación. El primero presenta a las Tabletas Bayer de Aspirina y Cafeína como el remedio para suprimir toda clase de dolores y de calmar la irritabilidad nerviosa resultante del "disfrute de la buena sociedad en la que prevalecen la hermosura, la gracia y el talento, con su obligado cortejo de alegría y de agudeza de ingenio". (...) Además, la pequeña dosis de Cafeína hace desaparecer la fatiga y el vértigo, llegando hasta constituir un antídoto del efecto desagradable de los vinos, licores $u$ otras bebidas alcohólicas o embriagantes".

Esta pieza publicitaria cobra más sentido para el lector del Diario de Costa Rica que unas páginas atrás quizá haya leído la crónica sobre "El Baile en el Teatro Nacional", al que concurrió lo más distinguido de la sociedad costarricense el 31 de diciembre de 1919. Ahí se insiste en varias ocasiones en la elegancia y sofisticación del evento y en las tendencias modernas en el vestido y el peinado:

También debemos hacer notar la nueva moda que se vió en gran mayoría en esta fiesta de no llevar las damas adorno alguno en la cabeza, los peinados fueron en su mayoría nuevos. ${ }^{23}$

De igual manera, se señala la variedad y modernidad de alimentos servidos en la cena encomendada al Hotel Washington: "consistió la cena en carnes frías, ensaladas, pastelillos de carne y de pollo, vinos tinto y blanco, sandwiches de diferentes clases, y todo cuanto podía pedir el buen gusto".

En el segundo anuncio, se deja entrever en la esquina inferior izquierda una hielera donde se enfría una botella de champán y unos puros en caja, problamente importados. Sentados a la mesa, tres caballeros vestidos de frac conversan con dos damas elegantemente ataviadas que lucen collares de perlas. Ambas muestran tocados al estilo de las Gibson Girls. El texto reproduce, en mucho, la cena en el Teatro Nacional celebrada tres días atrás y curiosamente guarda elementos en común con la ilustración titulada En el Savoy de Charles Dana Gibson. El anuncio indica:

Cuando en una mesa se agrega lo elegante del servicio, a lo selecto de los manjares y a lo delicado de los vinos el encanto de una conversación animada e ingeniosa, parece que todos aquellos placeres se hacen más intensos y experimentamos la

21 Diario de Costa Rica, 3 de enero de 1920 p. 6

22 Diario de Costa Rica, 8 de enero de 1920 p. 6

23 Diario de Costa Rica, 10 de enero de 1920 p. 3 
exquisita sensación que nace del sano deleite

de los sentidos mezclado con el regocijo espiritual.

Entre la ilustración y el texto se produce una complicidad que escenifica los placeres modernos. El consumo de bebidas alcohólicas, manjares exportados, vida social sofisticada y cosmopolita y, por lo tanto, exigente pueden resultar en consecuencias desagradables. El disfrute de la vida moderna es inseparable de nuevas prácticas de consumo asociadas a la sofisticación y variedad en las categorías de bebidas y alimentación. Vega Jiménez (2007: 25-27) se refiere a la venta de abarrotes y de bebidas alcohólicas en Costa Rica para este periodo:

De la totalidad de anuncios analizados, la venta de abarrotes ocupa el cuarto lugar con 63 registros de un total de 2077, luego de los medicamentos y la oferta de ropa. Se trata, en su mayoría, de avisos que dan cuenta de la existencia de múltiples alimentos procedentes, principalmente de de Europa (...) Los jamones, anchoas, arenques, además de los vinos y licores extranjeros, unidos a las jaleas, quesos y frutas secas, son expuestos a efecto de que sean adquiridos por personas de buen gusto que pretendan deleitar su paladar.

Exhibirse en la vida pública moderna puede también generar estrés y tensión nerviosa. Al igual que en el anuncio anterior, la Aspirina y Cafeína de Bayer ofrece un remedio eficaz ante las consecuencias de los deleites de la modernidad: “... aumentan los encantos de la vida, porque nos permiten gozar de ellos sin estar atormentados por el temor de sus desagradables consecuencias". Los anuncios analizados revelan un ethos moderno donde destacan mujeres y hombres sofisticados, cosmopolitas en fiestas opulentas.

Sin embargo, la publicidad de Bayer no pierde la oportunidad para afinar su segmentación y apelar, a hombres y mujeres con anuncios diferenciados. A las consumidoras alude con una retórica que, a la vez, alaba su rol central en la vida social moderna, como su frágil salud. "La flor de la vida social" ${ }^{24}$ destaca a la mujer que se distingue en las reuniones aristocráticas por su belleza, elegancia y su discreto ingenio y la describe como el mejor adorno de los salones distinguidos:

Desgraciadamente, las exigencias sociales afectan el delicado sistema de la mujer y alteran su salud, sobre todo durante la época en que sufre los efectos del proceso fisiológico que le es peculiar. Dolores de cabeza, cólicos depresión mental, fatiga y

24 Diario de Costa Rica 10 de enero de 1920 p 3 
malestar son los tormentos a los que se ve sometida la mujer en tales ocasiones. La vida entonces se convierte para ella en un martirio. Sus gracias se marchitan, su ingenio se embota y su capacidad de agradar disminuye.

Estas piezas se asemejan al tono publicitario utilizado en la publicidad de Bayer en el $A B C$ de Madrid para la misma época. Amabilidad ${ }^{25}$ representa a una mujer con mantilla mostrando el empaque de unas tabletas de Aspirina. Empieza por definir amabilidad como un estado de espíritu favorable a los demás y a uno mismo, seguidamente indica:

Desgraciadamente la vida moderna con sus inconvenientes, y la inexorable lucha por la existencia desequilibra nuestro estado normal, transformando nuestro buen humor y bienestar. Nos ponemos nerviosos, irritables, nos convertimos en víctimas de la neuralgia y de los dolores de cabeza, por ello nos sentimos disgustados después de asistir a cualquier fiesta y estamos sujetos a sufrir molestos y peligrosos resfriados.

El paralelo de los textos no deja de sorprender. En un temprano intento de segmentación por género, la publicidad de Aspirina Bayer aquí estudiada perfila los diferentes retos que tanto el hombre o la mujer modernos enfrentan y subrayan los beneficios que puede ofrecerles. En el primero, la mujer es la delicada flor de la vida social ${ }^{26}$. En el segundo ${ }^{27}$, Las amarguras de la vida, se describe cómo en los días que padece su proceso fisiológico es víctima de dolores, cólicos, malestares y nerviosismo, en este caso, se la representa en un espacio privado en solitario.

25 ABC de Madrid, 12 de febrero de 1920, p. 8

26 Diario de Costa Rica 10 de enero de 1920 p 3

27 Diario de Costa Rica 15 de enero p 6 


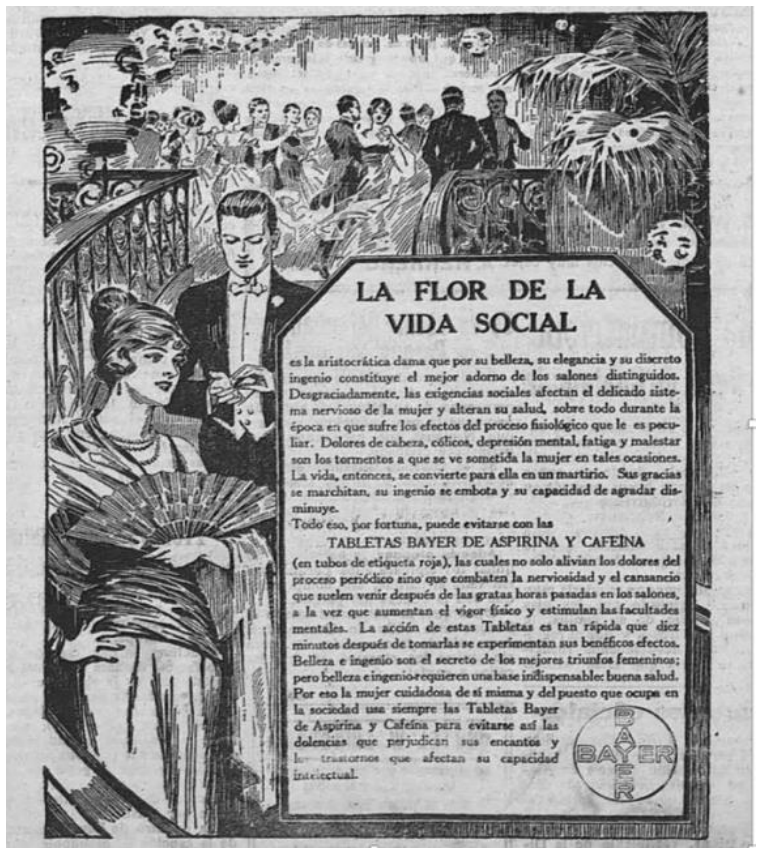

Figura 8. Diario de Costa Rica, 10 de enero de 1920, p. 3

El tercer anuncio ${ }^{28}$ vuelve a poner a la mujer en el espacio público, pero esta vez en un ambiente citadino moderno donde el pasearse en automóvil ofrece a la vez placer, pero puede amenazar su bienestar y salud:

La elegancia de la vida es la más ardiente pasión de la mujer moderna. El automóvil que representa hoy el ápice de la comodidad y la elegancia, proporciona a una dama satisfacciones y goces incomparables. En efecto ¿qué hay más grato para su vanidad que cruzar las calles en un "limousine" de último estilo, ni cuál de sus placeres se iguala al de vencer las distancias, con la rapidez del viento, en un carro de excursión.

El texto es casi un himno al futurismo, a su avidez por la velocidad y el movimiento, a la máquina que reta e implosiona el tiempo y el espacio de la ciudad moderna. Pero el cliché de género, advierte que la fragilidad del organismo femenino puede sucumbir a las tentaciones de la excursionista moderna:

Pero este placer tiene a veces sus desagradables consecuencias: una corriente de aire, un cambio inesperado de temperatura, el exponerse al frío con un traje ligero o cualquier otro descuido semejante, pueden ocasionar a la bella pasajera un resfriado con todas sus desagradables manifestaciones, tales como dolor de cabeza o de garganta, fiebre, escalofrío, postración nerviosa. Estas dolencias son 
más molestas para la mujer cuando coinciden con los cólicos y el malestar que generalmente acompañan al proceso fisiológico mensual.

El anuncio continúa no solo ofreciendo las tabletas de aspirina y cafeína como alivio a múltiples dolores, sino que también porque favorecen la circulación e incrementan el vigor físico y mental. Además, los beneficios solo tardan 10 minutos en hacer efecto. El automóvil es el fetiche del advenimiento de la era moderna. En Costa Rica se promocionaba la venta de automóviles y neumáticos de diferentes casas comerciales también en el Diario de Costa Rica por lo que el anuncio descrito anteriormente demuestra el interés del publicista en representar el ethos moderno con sus nuevos artefactos y las prácticas como el turismo en automóvil.

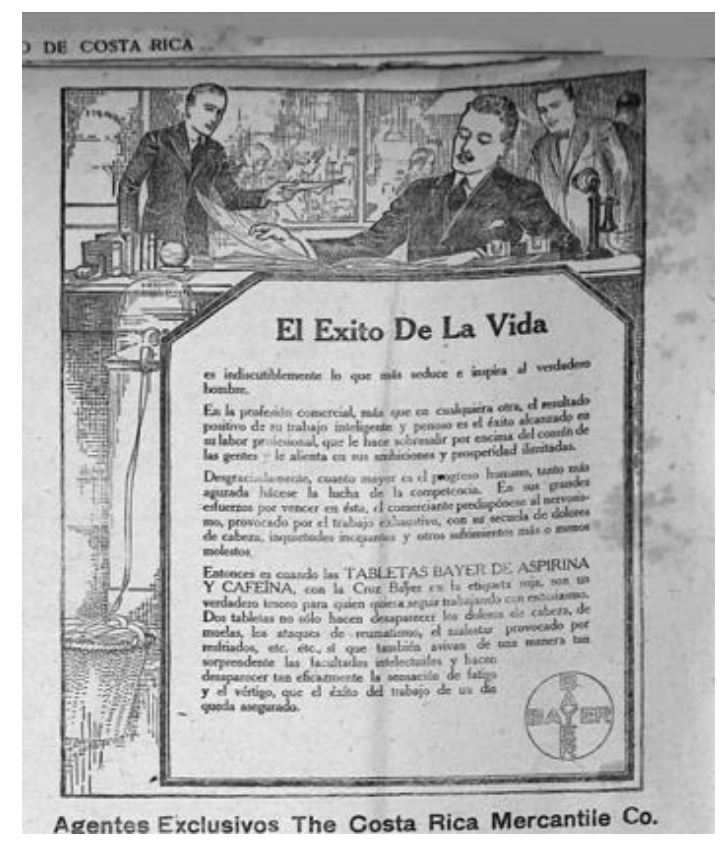

Figura 9. Diario de Costa Rica, 6 de enero 1920 p. 2

A las piezas anteriores se suman en enero y febrero, otras semejantes tales como la titulada" El éxito en La Vida", "La Potencia Vital" ${ }^{29}$ y el "Ingenio de la Vida" ${ }^{30}$. Destaca aquí el retrato del comerciante moderno, guiado por su "trabajo inteligente y penoso en el éxito alcanzado en su labor profesional que le hace sobresalir por encima del común de las gentes y le alienta en sus ambiciones y prosperidad ilimitada". Luego de posicionar al comerciante como un individuo, trabajador, competente y profesional, el texto describe las vicisitudes de la vida moderna y sus consecuencias:

Desgraciadamente cuanto mayor es el progreso humano, tanto más aguzada hácese la lucha de la competencia.

En sus grandes esfuerzos por vencer en ésta, el comerciante

29 Diario deCosta Rica 24 de enero de 1920 p 2

30 Diario deCosta Rica 28 de febrero de 1920 p 8 
predispónese al nerviosismo provocado por el trabajo

exhaustivo, con su secuela de dolores de cabeza, inquietudes incesantes y otros sufrimientos más o menos molestos.

La modernidad se sufre en el estrés y los nervios del individuo que, movido por su profesionalismo, quiere distinguirse de los demás. El discurso capitalista no puede ser más claro, en su afán de sobresalir, debe "luchar por competir", pero siguiendo la impronta moderna, como individuo destacado socialmente. La ilustración ofrece en un primer plano a tres hombres de mediana edad en una oficina, entre teféfonos y facsímiles, intercambiando y revisando documentos, en un segundo plano, divididas por una ventana de vidrio se pueden observar varias mujeres trabajando al parecer como secretarias. Una clara división del trabajo por género. Las tabletas de Aspirina y Cafeína son indispebables para quien quiera "seguir trabajando con entusiasmo":

Dos tabletas no solo hacen desaparecer los dolores de cabeza, de muelas, los ataques de reumatismo, el malestar provocado por resfriados, etc. etc. sí que también avivan de una manera tan sorprendente las facultades intelectuales y hacen desaparecer tan eficazmente la sensación de fatiga y el vértigo, que el éxito del trabajo de un día queda asegurado.

"La Potencia Vital" destaca también al individuo moderno. Las Tabletas de Aspirina y cafeína de Bayer se posicionan como un medicamento para enfrentar los retos que la modernidad impone al hombre contemporáneo:

La Potencia Vital es lo que hace valer y sobresalir al hombre en la Sociedad. Lo mismo en la profesión comercial que, en la carrera de ingeniería, lo propio en las artes y en el servicio diplomático, que alternando en la Sociedad ilustrada o elegante, lo que más precisa poseer es una potencial intelectual, física y moral de consistencia tan dura e inquebrantable como la que poseen las majestuosas montañas de estructura roquiza".

En el "El Ingenio en la Vida" la individualidad masculina moderna se representa en la figura del ingeniero y del inventor o científico que puede ver mermada su productividad e ingenio por las molestias que el urbanismo y la tensión que provocan nuevos inventos, artefactos y máquinas:

Desgraciadamente a medida que la civilización 
progresa, los sufrimientos del ser humano se acentúan

y frecuentemente impiden el libre desarrollo de su

ingenio. El ruido del tráfico, por ejemplo, enerva

a los trabajadores intelectuales ocasionándoles

dolores de cabeza e inquietud mental; cierta

negligencia en el cuidado de sus personas debida a

la excesiva atención requerida por los diversos

adelantos modernos en el mundo de las ciencias y

de los negocios, los expone a contraer refriados,

grippe, etc. con todas sus graves consecuencias.

Anuncios de Bayer semejantes a estos se pueden observar en la prensa norteamericana del mismo año tal como uno publicado en el Detroit Free Press el 19 de agosto donde se lee: "1920 Household expenses worry the average man..."

En síntesis, Bayer segmenta su publicidad por género para aliarse tanto a hombres y mujeres en conquista de la experiencia del ser y el hacer modernos, frente al rigor del trabajo, el deleite de la sofisticación o los avances técnicos que promete la nueva era.

\section{Consideraciones Finales}

La publicidad de Bayer en 1920 se encuentra en una difícil encrucijada internacional. Vencidas las patentes de sus productos estrella, enfrenta el asedio de su monopolio y recurre a herramientas mercadológicas: diferenciación, desarrollo de la identidad de marca, embalaje distintivo y utilización de narrativas publicitarias complejas que apelen a los consumidores modernos desde la razón (capacidad de discernimiento e inversión). Bayer cede a las condiciones que la industria farmacéutica y el campo médico imponen en cada país para regular la promoción de medicamentos a la vista de las más influyentes sociedades científicas y profesionales de médicos y farmacéuticos alrededor del mundo. La publicidad analizada privilegia entornos de consumo moderno, la modernidad es un deleite, pero a la vez impone a los individuos nuevas exigencias o extenuantes rutinas de trabajo o entretenimiento. Quedan muchas interrogantes que desbordarían este artículo en su objetivo inicial. Estudiar las condiciones de la industria farmacéutica costarricense de las primeras décadas del 1900, la producción y distribución internacional de las versiones no alemanas de la aspirina y su comercialización o contrabando y las condiciones y problemáticas particulares de su distribución en Costa Rica y Centroamérica son tareas pendientes para futuros trabajos de investigación en la historia económica de la cultura material y sus consecuencias en los imaginarios sociales. 


\section{Referencias Bibliográficas}

APPLEGATE, E. (1998): Personalities and Products: A Historical Perspective On Advertising in America. Greenwood Press.

BERGMAN K. C. Y RING, J. (eds) (2014): "History of Allergy" en Chemical Immunology and Allergy, Vol 100, 2014.

BOTEY, A. M. (2017): "La tardía epidemia de la influenza o gripe española y sus desenlaces en Costa Rica (1918 - 1920)" en Americania. Revista de Estudios Latinoamericanos Nueva Epoca (Sevilla), n.6, jul - dic 2017, pp.8-52. Disponible en Internet (1-21-2020): https://dialnet.unirioja.es/ejemplar/478178

BRUNE, K. y BURKHARD, H. (2004): "The discovey and development of antyinflammatory drug" En Arthritis and Rheumatology, Vol 50, No 8, 2004, pp 2391- 2399. Disponible en Internet

(1-21-2020): https://onlinelibrary.wiley.com/doi/full/10.1002/art.20424

DE GRAZIA, V. (2005): Irresistible Empire: America's Advantage through Twentieth Century Europe. Cambridge: Harvard University Press.

DYKSTRA, D. (1955). The Medical profession and patent and Proprietary Medicines During the Nineteenth Century. Bulletin of the History of Medicine Vol 29, No 5 , Septiembre - Octubre, 1955 pp $401-419$.

EDWARDS, J. (2011): "Yes, Bayer Promoted Heroin for Childern -Here Are The Ads that Prove It" enn Business Insider 17 de Noviembre. Disponible en Internet (1-212020): $\quad$ https://www.businessinsider.com/yes-bayer-promoted-heroin-forchildren-here-are-the-ads-that-prove-it-2011-11

FOX, S. (1984). The Mirror Makers: A History of American Advertising and its Creators. New York: Morrow.

JACOME ROCA, A. (2003): Historia de los Medicamentos. Bogotá: Academia Nacional de Medicina.

JEFFREYS, D. (2004): The Remarkable Story of a Wonder Drug. Aspirin Story. London: Bloomsbury Publishing.

LOGO LIFE (2020): Disponible en Internet (1-1-20202): https://issuu.com/bis_publishers/docs/logolife/6

MCTAVISH, J (1999): "What Did Bayer Do before Aspirin? Early Pharmaceutical Marketing Prectices in America" En Pharmacy in History, Vol 41, No. 1, pp 3-15. Disponible en Internet

en

(1-21-2020): 
https://www.jstor.org/stable/41111914?read-

now $=1 \&$ seq=9\#page scan tab contents

- (1987): “Aspirin in Germany. The Pharmaceitical Industry and the Pharmaceutical Profession in Pharmacy in Industry" en Pharmacy in History, Vol 29, No 3, pp 103 115. Disponible en Internet (1-1-2020): www.jstor.org/stable/41109885

MARCHAND, R (1985): Advertising. The American Dream. Berkeley: University of California Press.

SPICKA, M. E. (2007): Selling the Economic Miracle: Economic Reconstruction and Politics in West Germany, 1949 -1957. Oxford: Berghahn Books.

SPINKS, D. (2019): “Nostrum Remedium. A brief History of Pharmaceutical Marketing ". Disponible en Internet (1-21-2020): https://fluidic.agency/blog/nostrumremedium-a-brief-history-of-pharmaceutical-marketing/

PITZ, H. C. (1969): “Charles Dan Gibson. Delineator of An Age” en Gillon, E. V. Jr (1969). The Gibson Girl and Her America. New York: Dove Publication

RAVIÑA ROVIRA, E. (2008): Medicamentos: Un viaje a lo largo de la evolución histórica del decubrimiento de fármacos. Vol 1. Galicia: Universidad de Santiago de Compostela.

VEGA JIMENEZ, P. (2007): “El Reinado de la Publicidad. Historia de la Publicidad en los Periódicos de Costa Rica" 1900-1930" en En Patricia Vega (Comp.), Encrucijadas de la comunicación (pp. 3-31). San José: Editorial Universidad de Costa Rica. 